Article

\title{
Preparation and Characterization of
} $\mathrm{TiO}_{2}$-PVDF/PMMA Blend Membranes Using an Alternative Non-Toxic Solvent for UF/MF and Photocatalytic Application

\author{
Ouassila Benhabiles ${ }^{1,2}$, Francesco Galiano ${ }^{3, *}{ }^{-1}$, Tiziana Marino ${ }^{3}$, Hacene Mahmoudi ${ }^{4}$, \\ Hakim Lounici ${ }^{2,5}$ and Alberto Figoli ${ }^{3, *(\mathbb{D})}$ \\ 1 Department, Unité de Développement des Equipements Solaires, UDES /Centre de Développement des \\ Energies Renouvelables, CDER, Tipaza 42004, Algeria; benhabiles.ouassila@gmail.com \\ 2 Département génie de l'Environnement, Ecole Nationale Polytechnique, Alger 16200, Algérie; \\ hakim_lounici@yahoo.ca \\ 3 Institute on Membrane Technology (ITM-CNR), Via P. Bucci 17c, 87036 Rende (CS), Italy; t.marino@itm.cnr.it \\ 4 Faculty of Technology, University Hassiba Benbouali of Chlef, Chlef 02000, Algeria; \\ h.mahmoudi@univ-chlef.dz \\ 5 Faculty of Science, University of Bouira, Bouira 02180, Algeria \\ * $\quad$ Correspondence: f.galiano@itm.cnr.it (F.G.); a.figoli@itm.cnr.it (A.F.); Tel.: +39-0984-492027 (A.F.)
}

Academic Editor: Teresa Poerio

Received: 20 January 2019; Accepted: 16 February 2019; Published: 17 February 2019

\begin{abstract}
The approach of the present work is based on the use of poly (methylmethacrylate) (PMMA) polymer, which is compatible with PVDF and $\mathrm{TiO}_{2}$ nanoparticles in casting solutions, for the preparation of nano-composites membranes using a safer and more compatible solvent. $\mathrm{TiO}_{2}$ embedded poly (vinylidene fluoride) (PVDF)/PMMA photocatalytic membranes were prepared by phase inversion method. A non-solvent induced phase separation (NIPS) coupled with vapor induced phase separation (VIPS) was used to fabricate flat-sheet membranes using a dope solution consisting of PMMA, PVDF, $\mathrm{TiO}_{2}$, and triethyl phosphate (TEP) as an alternative non-toxic solvent. Membrane morphology was examined by scanning electron microscopy (SEM). Backscatter electron detector (BSD) mapping was used to monitor the inter-dispersion of $\mathrm{TiO}_{2}$ in the membrane surface and matrix. The effects of polymer concentration, evaporation time, additives and catalyst amount on the membrane morphology and properties were investigated. Tests on photocatalytic degradation of methylene blue (MB) were also carried out using the membranes entrapped with different concentrations of $\mathrm{TiO}_{2}$. The results of this study showed that nearly $99 \% \mathrm{MB}$ removal can be easily achieved by photocatalysis using $\mathrm{TiO}_{2}$ immobilized on the membrane matrix. Moreover, it was observed that the quantity of $\mathrm{TiO}_{2}$ plays a significant role in the dye removal.
\end{abstract}

Keywords: polymeric membranes; photocatalytic membranes; blend polymers; $\mathrm{TiO}_{2}$ catalyst; organic pollutants; non-toxic solvent

\section{Introduction}

Achieving a high water quality will be the next major environmental stress issue in the coming decades. Public opinion has evolved recently and demands better water quality and greater respect for the environment. Responding to these requirements the need of adopting new ecologically and environmentally friendly technologies is necessary. Green Chemistry, Green Energy, and Green Environment have been the objective of many researches during the last decades [1,2]. 
In 1987, the World Commission on Environment and Development introduced the concept of sustainable development, and in 1991, the term "green chemistry" was used for the first time by Anastas [3] as part of a special program launched by the Environmental Protection Agency of the United States (USEPA). Green chemistry, however, offers a scientifically-based set of solutions for protecting water quality, human health, and environment.

The treatment of colored wastewater from textile or dye industry is a serious problem that attracts the attention of many researchers. Dyes' removal by conventional treatment methods was found to be inadequate because most textile dyes have complex aromatic molecular structures which resist degradation [4]. Although various chemical and physical processes have been employed in the removal of dyes from effluents, they do not lead to a complete degradation of the dyes since most of the employed methods just transfer the contaminants from one phase to another one.

In the last decade, advanced oxidation processes (AOPs) have been growing since they are able to face the issues related to dye decomposition in aqueous systems [5]. The generation of hydroxyl radicals $\left({ }^{\bullet} \mathrm{OH}\right)$ oxidizing non-selectively various pollutants have improved the degradation of organic compounds compared to conventional methods. The irradiation in the presence of semi-conductors creates a red-ox environment able to destroy organic compounds present in aqueous solutions [6]. Among AOPs, degradation of organic compounds by heterogeneous photocatalysis is considered highly attractive. Titanium dioxide $\left(\mathrm{TiO}_{2}\right)$ is one of the most studied and used photocatalysts thanks to its good photocatalytic activity, high stability, low environmental impact, and low cost $[7,8]$. This catalyst can work under the form of powder suspended in a slurry or can be immobilized on various supports, such as glass, quartz, stainless steel [9], and recently membranes.

On the other hand, membrane technology has been already proved to be an alternative technology. The application of membrane processes not only enables high compounds removal efficiencies, but also allows the reuse of water and some of the valuable waste constituents. In the last few years, technical and economical improvements have made the treatment of industrial wastewater by membrane systems even more advantageous. Because of different benefits including high productivity and selectivity, compact and small size equipment, lower cost and energy consumption [10-12], the membrane process has found extensive applications in various fields including environment protection [13], petrochemical industry [14], biorefenery [15], desalination, and water treatment [16-20].

Despite the effectiveness of the membrane process, one of the main hurdles is represented by the decline of permeate flux due to the accumulation of various materials on the membrane surface. This phenomenon, caused by fouling and concentration polarization processes, leads to a reduction of membrane performance. Several approaches have been proposed so far in order to limit and mitigate fouling phenomenon during the treatment of wastewater [21-25]. Among these solutions, a promising method is coupling photocatalysis and membrane techniques [26]. A synergistic combination of photocatalysis and membrane filtration may provide a solution to enhance organics degradation and membrane permeability.

The combination of the membrane separation with the photocatalysis process is called photocatalytic membranes reactor (PMRs) and it represents an efficient, low cost and environmentally friendly technology with a great potential in water/wastewater treatment. In PMRs configurations, the catalysts can be immobilized on the membrane surface, entrapped in the membrane matrix or suspended in water $[27,28]$. Most of the works have focused on the use of $\mathrm{TiO}_{2}$ photocatalysts suspended in water [29]. However, the main technical barriers to its commercialization are represented by the fact that the photocatalysts need to be separated from the suspension causing an increase in the operating costs and a decrease of the treatment efficiency [30]. A promising solution to this problem is to use $\mathrm{TiO}_{2}$ photocatalysts entrapped within the membrane matrix.

A great number of organic polymers are commercially available for the preparation of ultrafiltration (UF) membranes by phase inversion method. Among these polymers, poly (vinylidene fluoride) (PVDF) is a semi-crystalline polymer with widespread applications thanks to its excellent properties such as good mechanical strength, stability against harsh chemicals and good thermal 
stability [31,32]. However, the high hydrophobic nature and the low fouling resistance of PVDF membranes (due to protein adsorption on their surface) limit their use in water treatment processes. Many studies have been devoted in improving or varying PVDF membranes properties adopting several techniques such as physical blending, chemical grafting, and surface modifications [33-35].

Among these various methods, the blending with various polymers has the advantage of easy preparation by the phase inversion technique. The addition of a second polymer to the casting dope solution is known to be very effective on the modification of membranes structure and characteristics, such as the formation of macrovoids, which produces different behaviors in filtration [33].

PVDF is highly miscible with oxygen containing polymers, thanks to the interaction between the fluorine atoms and carbonyl groups of the partner polymer [36,37]. Several pairs of blends have been investigated, such as PVDF/poly(vinylpyrrolidone) (PVP), PVDF/ poly (ethylene glycol) (PEG), PVDF/ poly(vinylacetate) and PVDF/poly(methylmethacrylate) (PMMA) [38]. Among these polymers, PMMA is one of the most interesting due to its good compatibility with PVDF by simultaneous precipitation in a water bath all over the concentration range [37,39-43]. The produced blend membranes exhibited improved hydrophilicity and water permeation fluxes with respect to pure PMMA membranes [44]. The blend of PVDF with PMMA was investigated by several authors due to the possibility to combine the benefits of both polymers (improving mechanical resistance, processability, and ionic conductivity) [45-48]. However, a systematic study aiming to evaluate the effect of preparation parameters (such as evaporation time, polymer concentration and presence of pore formers) is still missing. Moreover, the potential photocatalytic activity of PVDF/PMMA membranes loaded with $\mathrm{TiO}_{2}$ nanoparticles is an unexplored area.

Considering that photocatalytic composite membranes using alternative solvents have not been thoroughly investigated, the preparation of nano-composite blend PVDF/PMMA membranes containing $\mathrm{TiO}_{2}$ using a more compatible solvent is reported and discussed in this work for the first time.

In order to preserve the environment from the risks posed by conventional toxic solvents [49], triethyl phosphate (TEP) has been, therefore, used as much less harmful alternative solvent, in accordance to the concept of sustainable development and green chemistry principles [50]. TEP is not teratogenic, carcinogenic, or mutagenic, and as stated in its Safety Datasheet "contains no components considered to be either persistent, bioaccumulative and toxic, or very persistent and very bioaccumulative at levels of $0.1 \%$ or higher [ $[51]^{\prime \prime}$.

So far, there are only five articles concerning the use of TEP, as only solvent, for the production of PVDF membranes applied in membrane distillation but none of them dealing with water purification [52-56]. $\mathrm{TiO}_{2}-\mathrm{PVDF} / \mathrm{PMMA} / \mathrm{TEP}$ membranes were prepared via the phase-inversion method. Scanning electron microscopy (SEM) was used to characterize the surface and cross-section morphology of the membranes. Pore size, pure water permeability (PWP), mechanical strength, porosity, and contact angle measurements were also carried out. The photocatalytic activity of the membranes was evaluated by following the methylene blue (MB) degradation in water under UV light irradiation.

\section{Results and Discussion}

\subsection{Cloud Point Measurement}

This work describes, for the first time, the preparation of PVDF/PMMA membranes using TEP as a solvent. However, the ability of TEP to dissolve PVDF has been already studied in previous works through the comparison of their Hansen solubility parameters [52,56]. The solubility parameter of TEP $\left(22.2 \mathrm{MPa}^{1 / 2}\right)$, in fact, is very close to the one of PVDF $\left(23.2 \mathrm{MPa}^{1 / 2}\right)$ confirming that a PVDF-TEP solution is thermodynamically favored.

A large number of studies have focused on the phase diagrams of PVDF solutions in relation to the cloud point temperature at which a clear polymer solution becomes more viscous and cloudy [57-59]. Opacity can occur in a polymer solution due to the separation between lean and polymer-rich phases, 
and this process is known as liquid-liquid phase separation (L-L). In our PVDF/PMMA/PET systems, the solutions turned cloudy and then started to form gels at the sol-gel transition temperature, as described in Figure 1.

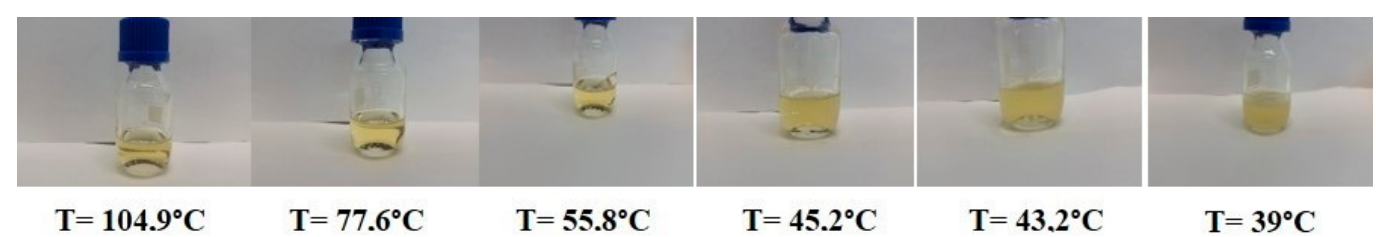

Figure 1. Visible phase change for a $12 \%$ polymer concentration solution.

The sol-gel transition temperatures measured for TEP as a function of the concentration of PVDF/PMMA are presented in Figure 2. The obtained results show that the sol-gel transition temperature increased at higher PVDF/PMMA concentrations and it was ranging from 43 to $55^{\circ} \mathrm{C}$. This can be explained by the fact that a higher temperature is required to keep the polymer/solvent system homogeneous when the concentration of polymer is increased.

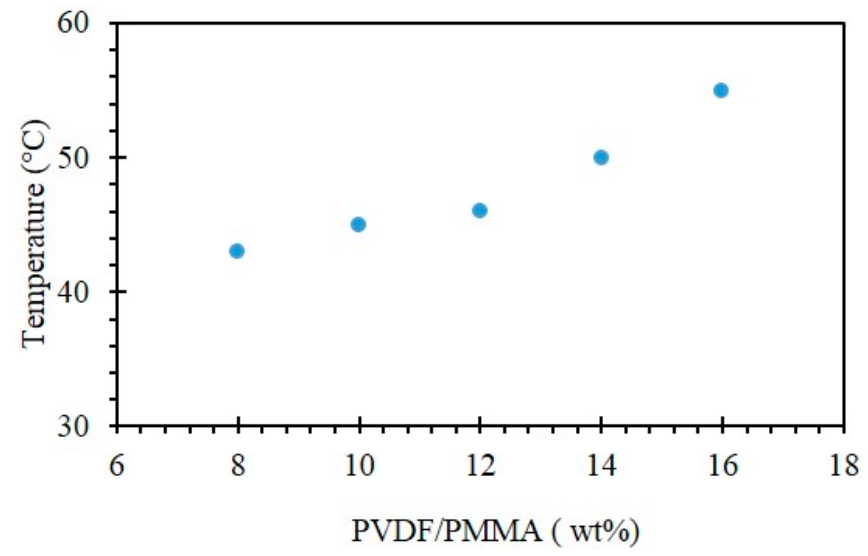

Figure 2. Sol-gel transition temperature for different concentrations of PVDF/PMMA (poly (vinylidene fluoride/poly (methylmethacrylate)).

Same trend was observed by Sawada et al. [59] for the preparation of PVDF membranes via TIPS using three non-toxic citrate-based solvents. For all the solvents evaluated in this study, the sol-gel transition temperature increased with the increase of PVDF concentration.

\subsection{Characterization of the Membranes}

The effect of some crucial parameters like evaporation time, amount of polymer, additives and quantity of $\mathrm{TiO}_{2}$ was investigated. The influence they played in membrane morphology, performance and properties was investigated and discussed.

\subsubsection{Effect of Evaporation Time}

The time required to evaporate the solvent from the polymer solution during the phase-inversion process is known as evaporation time. This is one of the main parameters in membrane manufacturing which can be tuned in order to produce the desired morphology in porous membranes. The membrane morphology has a significant effect on the structural properties and performance of UF/microfiltration (MF) membranes. The influence of evaporation time was, therefore, investigated for the membranes M1, M2, and M3 whose composition is reported in Table 1. 
Table 1. Characterization of the M1-M3 membranes.

\begin{tabular}{ccccc}
\hline Membrane Code & Porosity (\%) & $\begin{array}{c}\text { Mean Flow Pore } \\
\text { Diameter }(\boldsymbol{\mu m})\end{array}$ & $\begin{array}{c}\text { Young's Modulus } \\
\mathbf{N} / \mathbf{m m}^{2}\end{array}$ & Contact Angle $\left(^{\circ}\right)$ \\
\hline M1 & $80 \pm 1$ & $0.08 \pm 0.05$ & $87 \pm 1$ & $98 \pm 1$ \\
\hline M2 & $82 \pm 1$ & $0.19 \pm 0.1$ & $81 \pm 1$ & $120 \pm 3$ \\
\hline M3 & $87 \pm 1$ & $0.32 \pm 0.2$ & $55 \pm 2$ & $123 \pm 3$ \\
\hline
\end{tabular}

Flat sheet membranes were prepared using the same dope solution and three different evaporation times, ranging from 0 to $5 \mathrm{~min}$, were considered. The membranes, after casting, were immersed immediately in the coagulation bath (membrane M1, NIPS) or exposed for 2 min $30 \mathrm{~s}$ or 5 min to a relative humidity before the precipitation of the polymer in water (membrane M2 and M3, NIPS-VIPS).

Figure 3 show SEM images of top, bottom and cross-section of the different investigated membranes. Due to the good miscibility of PVDF and PMMA, all the prepared membranes did not show any phase separation. The morphology of M1 membrane revealed an asymmetric structure with a homogeneous and uniform dense layer overlying a porous and thicker structure. The denser top layer is the result of the fast solvent/non-solvent demixing rate occurring for the M1 membrane prepared by NIPS as a consequence of the immediate immersion of the cast film in the water coagulation bath. The exposure of the nascent films (M2 and M3 membranes) to humidity, on the contrary, slowed down the precipitation process fostering the formation of a more porous surface visible in Figure $3 \mathrm{~d}, \mathrm{~g}$.
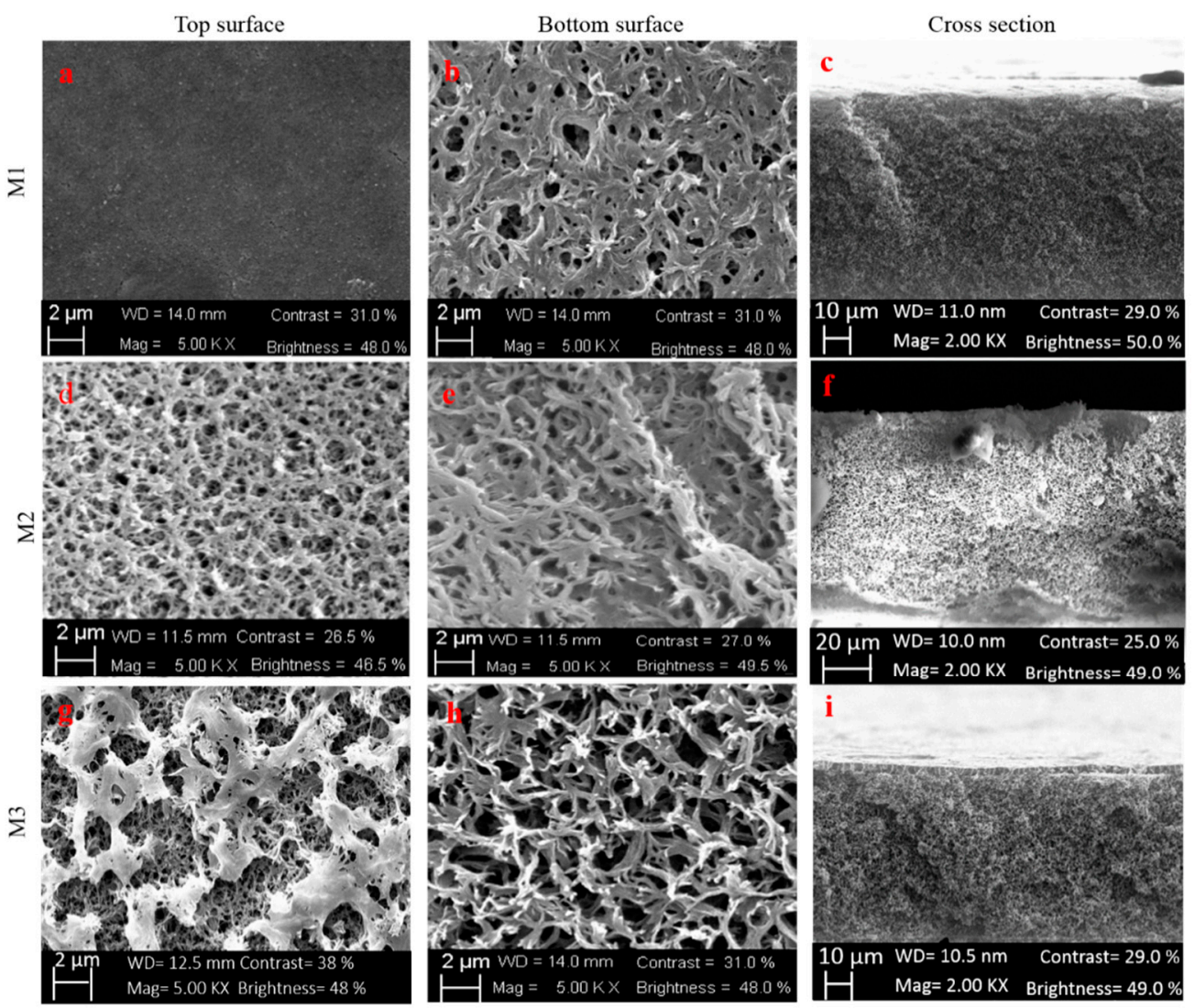

Figure 3. SEM images: top surface, bottom surface and cross-sections of membranes M1, M2, and M3.

All membranes presented a porous and sponge-like structure along the cross section (for higher magnification see the Supporting Material Figure S1). M3 membrane (Figure 3i), however, showed an asymmetric structure: a thin layer at the top surface in the form of macrovoids and a sponge-like structure across the rest of the membrane. 
The evaporation time (different from 0 ) significantly changed the morphology of the membrane surface and also the nature of the sponge-like structure. Similar results were observed by A. Ali et al. [60] which reported that the effect of evaporation time considerably altered the morphology and structure of membranes made from a mixture of polysulfone/cellulose acetate phthalate/polyvinylpyrrolidone (PSf/CAP/PVP). The change in the membrane morphological structure with increasing evaporation time is due to the movement of the volatile solvent on the surface of the spread film. Increasing the evaporation time, more solvent was removed from the surface of the membrane. In this phenomenon, a homogeneous and more concentrated nascent skin layer was formed due to the coalescence and melting of the separated dry phase structure. This type of skin layer has a high resistance to solvent and non-solvent mass transfer between the coagulation bath and the inner region of the membrane during the wet phase inversion process [61].

The trend of PWP of the membranes (presented in Figure 4) confirmed what observed in SEM pictures and it was also in agreement with the characterization tests reported in Table 1.

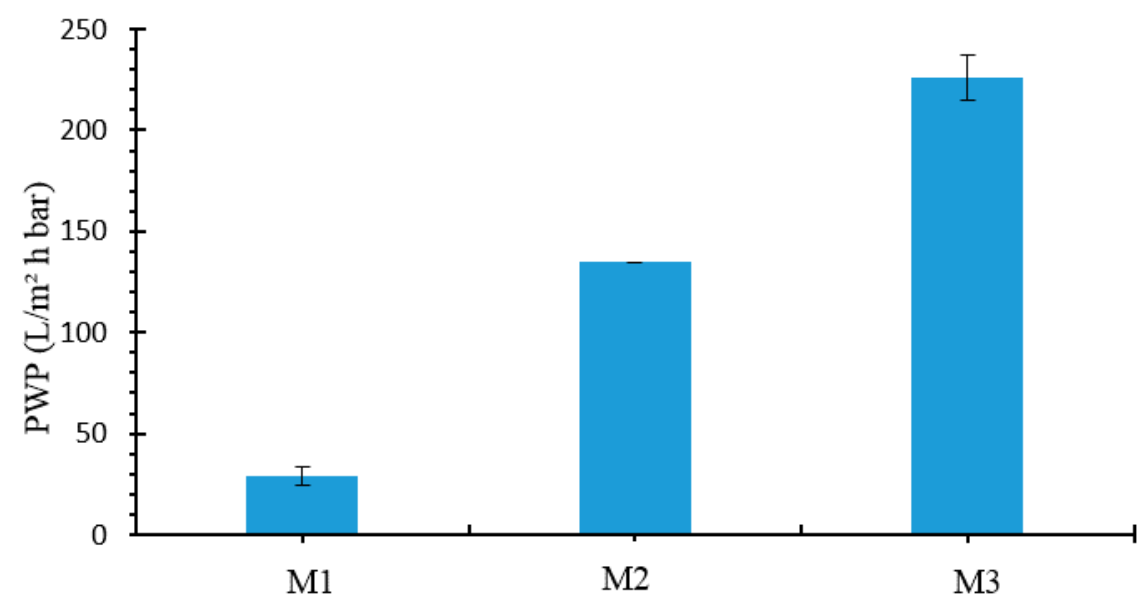

Figure 4. Pure water permeability (PWP) of membranes with different evaporation time.

The PWP, in fact, increased from $29 \mathrm{~L} / \mathrm{m} 2 \mathrm{~h}$ bar to $226 \mathrm{~L} / \mathrm{m} 2 \mathrm{~h}$ bar by increasing the evaporation time of the membrane. This was due to an enhancement in membrane pore size (from $0.08 \mu \mathrm{m}$ for $\mathrm{M} 1$ to $0.32 \mu \mathrm{m}$ for M3) and porosity (from $80 \%$ for M0 to $87 \%$ for M3). The increase in pore size during the VIPS process is a very well known phenomenon. The higher exposure time, in fact, lowers solvent-non-solvent demixing delaying polymer precipitation and, thus, favoring an increase in membrane pore size and porosity [62]. The membrane pore size was in the range of MF/UF.

The mechanical properties of the membranes, however, decreased by increasing the evaporation time. The Young's modulus dropped from 87 to $55 \mathrm{~N} / \mathrm{mm}^{2}$ as a result of the increased porosity of the membranes. This is in agreement with what generally observed in literature. The presence of macrovoids (as in M3) and the increase of the overall void fraction (as in M2 and M3) represent weak points into the membrane leading to a decrease in membrane mechanical resistance [63].

All the three membranes presented a contact angle higher than $90^{\circ}$ (from 98 to $123^{\circ}$ ) as a consequence of the polymers used for their fabrication. PVDF and PMMA, in fact, are both hydrophobic polymers conferring to the membranes a hydrophobic moiety. The difference in contact angle from M1 to M3 membrane can be justified by their different surface morphology. M2 and M3 membranes, in fact, presented a porous surface in comparison to M1 characterized by a denser and more compact topography. Besides surface topography, membranes having higher pore size shows also higher surface roughness [64-67].

The higher roughness of porous membranes can be responsible of the hydrophobicity reinforcement [68] according to the phenomenological model proposed by Wenzel [69].

The intermediate evaporation time of $2.5 \mathrm{~min}$ (M2 membrane) was considered and kept constant for the preparation of the following M4-M8 membranes. 


\subsubsection{Effect of Polymer Content}

The polymer concentration is one of the fundamental parameters in the manufacturing of membranes strongly affecting their morphology and their retentive capacity. In this study, three different concentrations of the PVDF-PMMA blend were considered: 10, 12, and $14 \mathrm{wt} \%$. All the membranes were prepared by keeping constant the evaporation time at 2.5 min (M2, M4, and M5 membranes whose complete composition is reported in Table 6).

Figure 5 illustrates top surface, bottom surface and cross-sections of the investigated membranes. M2 and M4 membranes, prepared with 12 and $10 \mathrm{wt} \%$ of polymers concentration, respectively, presented a very porous surface for both top and bottom side (as showed in Figure 5a,b,d,e). The membrane surface of M5 prepared with $14 \mathrm{wt} \%$ of polymers concentration (Figure $5 \mathrm{~g}$ ), however, was quite different. Increasing the polymer concentration, in fact, a less-porous surface was observed. The reduction of cavities as a consequence of polymer concentration increase is a very well documented phenomenon [63,70]. High polymer concentrations, in fact, slow down the precipitation process of the membrane leading to the formation of a membrane with a denser top layer and lower pore size [71]. The cross-section of the membranes revealed a sponge-like structure (for higher magnification see the Supporting Material Figure S2).
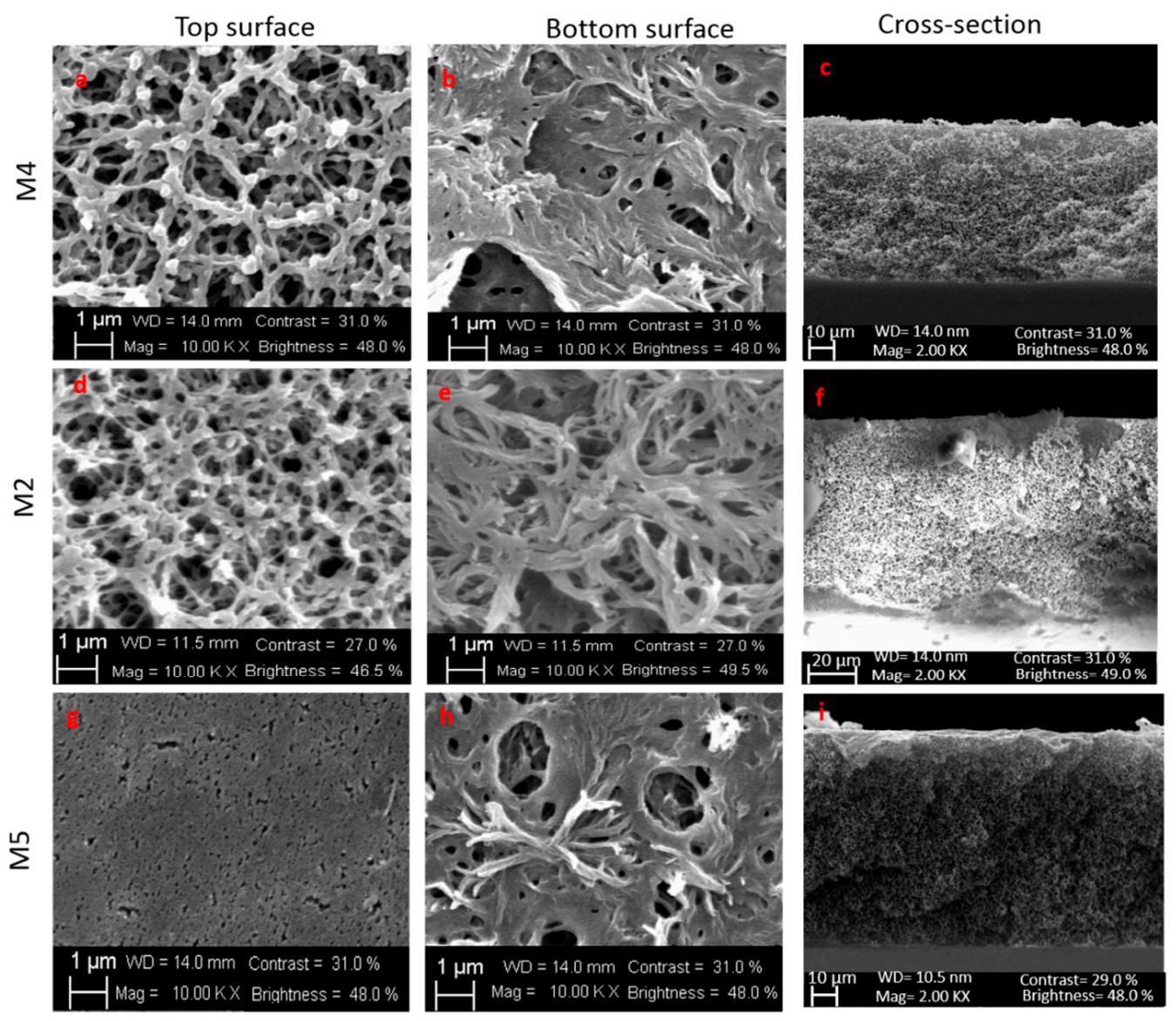

Figure 5. SEM images: top surface and bottom surface of membranes M4, M2, and M5.

As indicated in Table 2, the highest polymer concentration (14 wt \%) caused, as expected, an increase in the viscosity of the dope solution (from 388 to $2133 \mathrm{cP}$ ). This increase slowed down the growth of the porous structures, resulting in a reduction of the pore size and consequently in a reduction of the porosity (from 85 to $82 \%$ ). 
Table 2. Membrane characterization of membranes prepared at different polymer content.

\begin{tabular}{ccccccc}
\hline $\begin{array}{c}\text { Membrane } \\
\text { Code }\end{array}$ & $\begin{array}{c}\text { Viscosity } \\
(\mathbf{c P})\end{array}$ & $\begin{array}{c}\text { Thickness } \\
(\mathbf{m m})\end{array}$ & Porosity $(\mathbf{\%})$ & $\begin{array}{c}\text { Mean Flow Pore } \\
\text { Diameter }(\boldsymbol{\mu m})\end{array}$ & $\begin{array}{c}\text { Young's Modulus } \\
\left(\mathbf{N} / \mathbf{m m}^{2}\right)\end{array}$ & $\begin{array}{c}\text { Contact Angle } \\
\left({ }^{\circ}\right)\end{array}$ \\
\hline M4 & 388 & $0.056 \pm 0.012$ & $85 \pm 1$ & $0.40 \pm 0.2$ & $84 \pm 2$ & $124 \pm 1$ \\
\hline M2 & 645 & $0.072 \pm 0.008$ & $82 \pm 1$ & $0.19 \pm 0.1$ & $81 \pm 1$ & $120 \pm 3$ \\
\hline M5 & 2133 & $0.077 \pm 0.006$ & $82 \pm 1$ & $0.18 \pm 0.2$ & $142 \pm 12$ & $111 \pm 1$ \\
\hline
\end{tabular}

The cross-section of all the three membranes (Figure $5 c, f, i)$ was mainly represented by a sponge-like structure even if in M5 membrane is visible the denser skin layer.

All the membranes exhibited a hydrophobic nature as a consequence of the polymers used for their preparation. Even in this case, the lower contact angle exhibited by M5 membrane can be related to its smoother and more compact surface in comparison to M2 and M4.

\subsubsection{Effect of Additives}

Several studies have been carried out showing the effect of additives on the structure and the performance of UF PVDF membranes [72]. The performance and the membrane structure can be controlled by the composition of the dope solution and other membrane preparation conditions. In Table 3, the effect of additives (PEG-200 and PVP-K17) was studied for two membranes (M0 and $\mathrm{M} 2)$ prepared at the same polymers concentration ( $12 \mathrm{wt} \%$ ) and same evaporation time (2.5 $\mathrm{min})$. M0 membrane did not contain any additive, while M2 membranes contained $25 \mathrm{wt} \%$ of PEG200 and $5 \mathrm{wt} \%$ of PVP-K17 both very well known to act as porogens.

Table 3. Characterization of membranes prepared without and with additives.

\begin{tabular}{ccccccc}
\hline $\begin{array}{c}\text { Membrane } \\
\text { Code }\end{array}$ & $\begin{array}{c}\text { Viscosity } \\
(\mathbf{c P})\end{array}$ & $\begin{array}{c}\text { Thickness } \\
(\mathbf{m m})\end{array}$ & Porosity (\%) & $\begin{array}{c}\text { Mean Flow Pore } \\
\text { Diameter }(\boldsymbol{\mu m})\end{array}$ & $\begin{array}{c}\text { Young's Modulus } \\
(\mathbf{N} / \mathbf{m m})\end{array}$ & $\begin{array}{c}\text { Contact Angle } \\
\left({ }^{\circ}\right)\end{array}$ \\
\hline M0 & 228 & $0.061 \pm 0.004$ & $78 \pm 1$ & $0.07 \pm 0.05$ & $90 \pm 1$ & $110 \pm 2$ \\
\hline M2 & 645 & $0.072 \pm 0.008$ & $82 \pm 1$ & $0.14 \pm 0.1$ & $81 \pm 1$ & $120 \pm 3$ \\
\hline
\end{tabular}

The additives used did not greatly affect the overall wettability of the membrane. PVP and PEG are hydrophilic agents which can improve the hydrophilic nature of the membrane. However, during the membrane post-treatment they are washed away and removed from the membrane matrix being both soluble in water. This process can, therefore, nullify their hydrophilic behavior on the membrane. The different values in contact angle between $\mathrm{M} 0$ and $\mathrm{M} 2$ can therefore be attributed to the different morphology exhibited by both membranes as can be seen in Figure 6 .
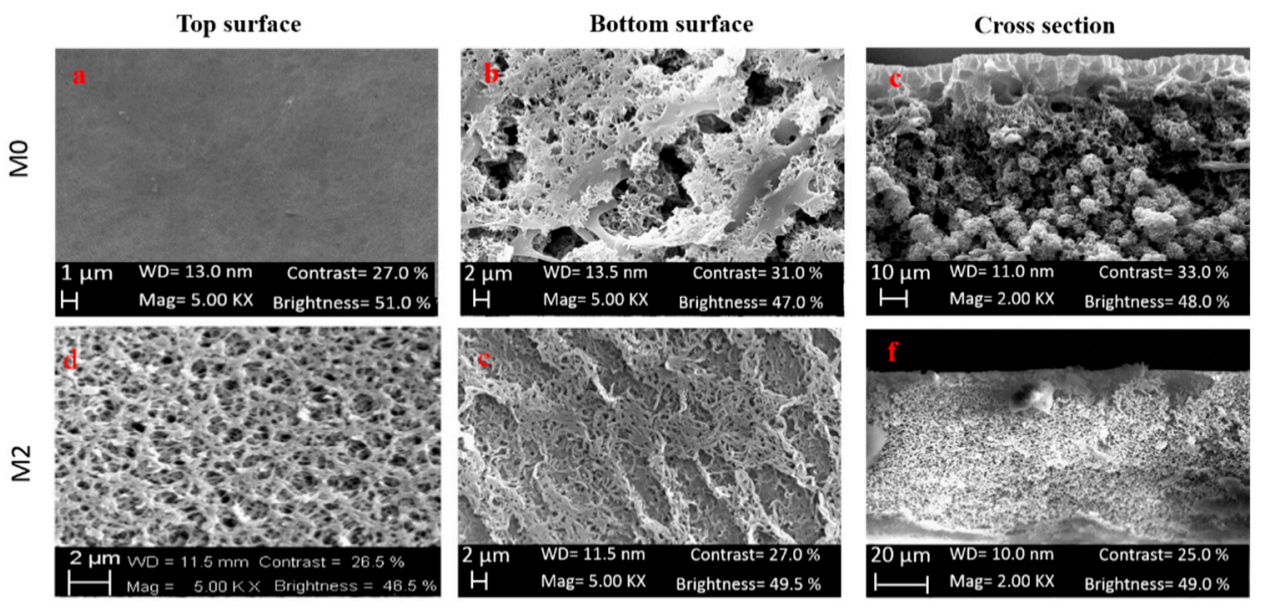

Figure 6. SEM images: top surface, bottom surface and cross-section of membranes M0 and M2. 
The presence of additives, as expected, promoted an increase in porosity (from 78 to $82 \%$ ) and in membrane pore size (from 0.07 to $0.14 \mu \mathrm{m}$ ).

Additives with a concentration ranging from 5 to $20 \mathrm{wt} \%$, are also generally responsible of membrane thickness increase as a consequence of dope solution viscosity increase and the formation of a more compact structure [73-75]. The addition of the additives, in fact, induced an increase in the dope solution viscosity (from 228 to $645 \mathrm{cP}$ ) (almost 3 times higher) and the formation of a denser kin layer (Figure 6). As can be seen in cross-section pictures (Figure 6c,f), the morphology of the membrane varied from a spherulitic structure (in case of M0) to a sponge-like structure (in case of M2). SEM magnification of membranes top layer is shown in Figure S3 of the Supporting Material.

The Young's module decreased from 90 to $81 \mathrm{~N} / \mathrm{mm}^{2}$ as a consequence of additives addition in the membrane matrix due to the increase of the overall void fraction.

\subsubsection{Effect of $\mathrm{TiO}_{2}$ Amount}

The $\mathrm{TiO}_{2}$ concentration generally ranges between 0 and $5 \mathrm{wt} \%$ by according to various studies reported in literature [45,76-83]. In the present research, membranes containing different amounts of $\mathrm{TiO} 2(0.12,0.25$ and $0.5 \mathrm{wt} \%)$ were prepared. Table 6 reports the different formulations of the dope solutions used for the membranes prepared at different TiO2 concentrations (M6, M7, and M8) and at the same evaporation time of $2.5 \mathrm{~min}$.

The dispersion of inorganic nanoparticles in the polymer matrix is an important characteristic of organic/inorganic composites. The SEM-BSD analysis was used to map the inter-dispersion of $\mathrm{TiO} 2$ particles on the surface and membrane matrix. Figure 7 shows SEM-BSD images of the surfaces and cross-sections of TiO2-PVDF/PMMA nano-composites membranes prepared by phase inversion compared with a control sample without catalyst (M2).

No clear particle aggregation was observed in the cross sections of the composites, indicating that the $\mathrm{TiO} 2$ nanoparticles were well dispersed in the polymer matrix. These results are similar to the ones reported by Zho et al. [82] for PVDF/PMMA/TiO2 composite membranes prepared by in situ polymerization. Even if some areas of the membranes contained $\mathrm{TiO} 2$ aggregations, as shown in Figure 7(c4), $\mathrm{TiO} 2$ particles were generally well dispersed not only on the surfaces but also throughout the membrane cross-section (Figure 7(c2-4)).

TiO2-PVDF/PMMA nano-composites membranes were characterized by pore size diameter, contact angle, porosity, and mechanical strength (Table 4). By increasing the amount of $\mathrm{TiO}_{2}$, the hydrophilicity of the membrane was enhanced as a consequence of the hydrophilic moiety of the nanoparticles [84]. Moreover, the addition of $\mathrm{TiO} 2$ led to a general improvement in membrane Young's modulus value in comparison to the unloaded membrane M2. As reported in several works $[83,85,86]$, in fact, the introduction of $\mathrm{TiO} 2$ nanoparticles enhances the mechanical resistance of the membranes by acting as cross-linkers between the polymer chains increasing their rigidity and, as a consequence, their mechanical resistance. The $\mathrm{TiO} 2$ nanoparticles can, in fact, interact via hydrogen bond between the hydroxyl group present on the surface of $\mathrm{TiO} 2$ and oxygen groups of PMMA $[87,88]$.

The pore size of the membranes increased as the increase of $\mathrm{TiO} 2$ (from $0.14 \mu \mathrm{m}$ for M2 to $0.42 \mu \mathrm{m}$ for M8). The increase in pore size after the addition of $\mathrm{TiO}_{2}$ can be related to the formation mechanism of the membranes. The $\mathrm{TiO}_{2}$ nanoparticles have a hydrophilic nature and this could promote the attraction and penetration of water vapor from the environment during the VIPS process favoring the increase in membrane pore size [86]. 

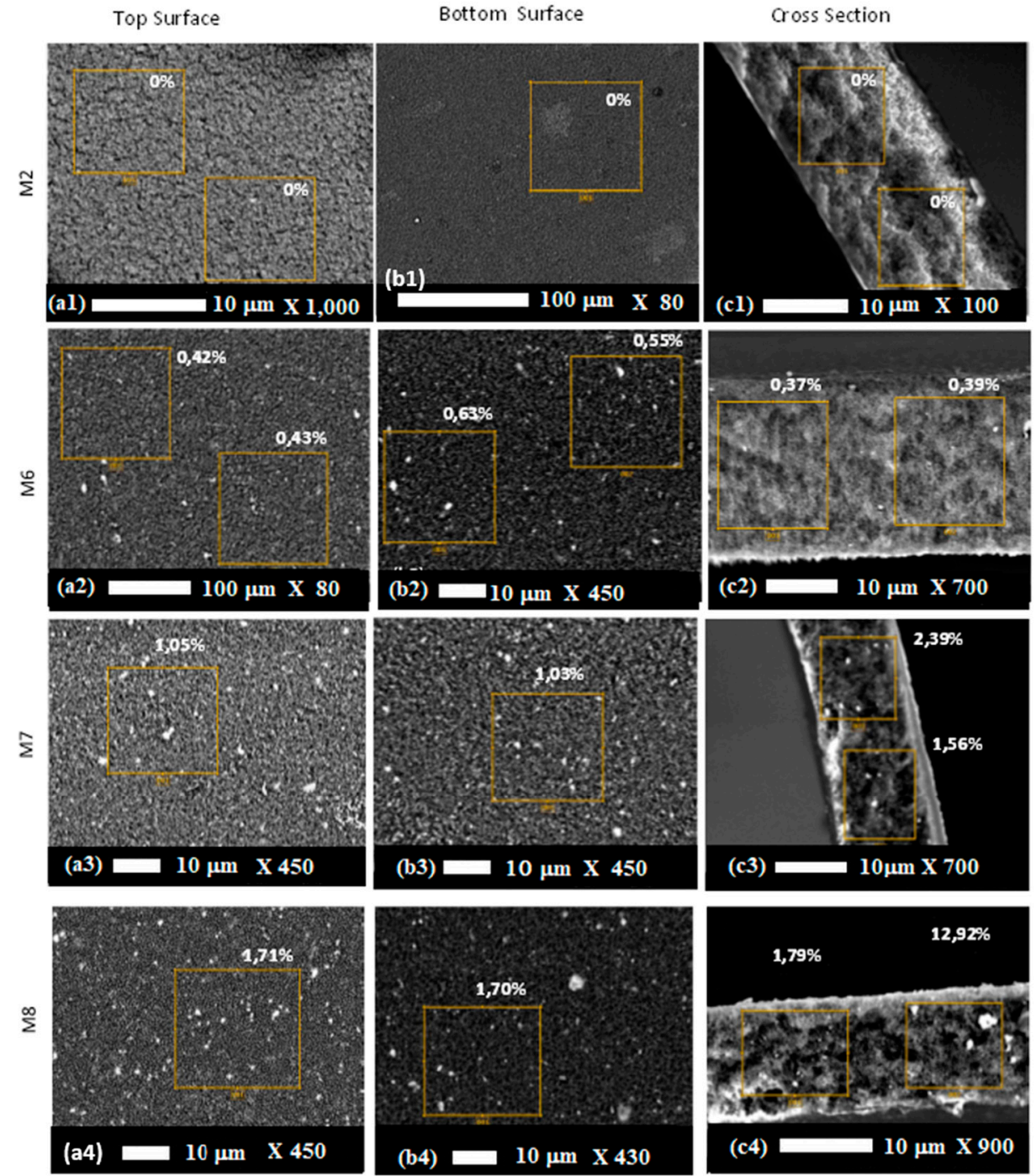

Figure 7. SEM-BSD (backscatter electron detector) pictures for $\mathrm{TiO}_{2}$ particles distribution on top surfaces (a), bottom surfaces (b) and cross sections (c) of M2, M6, M7, and M8 membranes.

Table 4. Membrane characterization for different amounts of $\mathrm{TiO}_{2}$.

\begin{tabular}{cccccc}
\hline $\begin{array}{c}\text { Membrane } \\
\text { Code }\end{array}$ & $\begin{array}{c}\text { Thickness } \\
(\mathbf{m m})\end{array}$ & $\begin{array}{c}\text { Porosity } \\
(\mathbf{\%})\end{array}$ & $\begin{array}{c}\text { Mean Flow Pore } \\
\text { Diameter }(\boldsymbol{\mu m})\end{array}$ & $\begin{array}{c}\text { Young's Modulus } \\
\left(\mathbf{N} / \mathbf{m m}^{2}\right)\end{array}$ & $\begin{array}{c}\text { Contact Angle } \\
\left({ }^{\circ}\right)\end{array}$ \\
\hline $\mathbf{M} 2-\mathbf{T i}$ & $0.072 \pm 0.008$ & $82 \pm 1$ & $0.14 \pm 0.1$ & $81 \pm 1$ & $120 \pm 3$ \\
\hline $\mathbf{M 6 - 0 . 1 2 T i}$ & $0.063 \pm 0.003$ & $80 \pm 1$ & $0.35 \pm 0.2$ & $114 \pm 5$ & $102 \pm 4$ \\
\hline $\mathbf{M 7 - 0 . 2 5 T i}$ & $0.068 \pm 0.011$ & $81 \pm 1$ & $0.41 \pm 0.25$ & $99 \pm 7$ & $98 \pm 4$ \\
\hline $\mathbf{M} 8-\mathbf{0 . 5 0 T i}$ & $0.055 \pm 0.008$ & $83 \pm 1$ & $0.42 \pm 0.15$ & $104 \pm 3$ & $93 \pm 5$ \\
\hline
\end{tabular}

\subsection{Photocatalytic Performance}

Before carrying out the photocatalytic tests with $\mathrm{MB}$, the resistance of the blend membranes to UV irradiation was evaluated in order to exclude any possible photodegradation of the polymer matrix. The tests were carried out with the M8 membrane, containing the highest concentration of $\mathrm{TiO}_{2}$, by measuring its starting PWP. Then, the membrane sample was exposed for $3 \mathrm{~h}$ to UV light irradiation. After this period, the PWP was measured again. No changes in the recorded values of PWP (about $780 \mathrm{~L} / \mathrm{m}^{2} \mathrm{~h}$ bar), before and after the exposure to UV light irradiation, were observed (see Figure S4 of the Supporting Material). From the constancy of membrane performance, the resistance of the 
membrane to UV light was, therefore, assessed. In case of photodegradation of the polymer, in fact, an increase in water permeability should have been observed. The higher PWP of M8 membrane in comparison to M1, M2, and M3 can be attributed to its higher pore size and lower contact angle as a consequence of $\mathrm{TiO} 2$ addition.

The photocatalytic activity of TiO2-PVDF/PMMA prepared membranes was studied by evaluating the photodegradation of the model dye MB. The photocatalytic performance of the membranes was evaluated by measuring the concentration of MB during $300 \mathrm{~min}$ of UV lamp (Zp type $500 \mathrm{~W}$ ) irradiation.

In order to examine the effect of $\mathrm{TiO} 2$ catalyst incorporated in photocatalytic membranes matrix, a membrane without $\mathrm{TiO} 2$ was also used (M2) under the same operating conditions. The variation in $\mathrm{MB}$ concentration as a function of $\mathrm{UV}$ irradiation time in the presence of different membranes is shown in Figure 8.

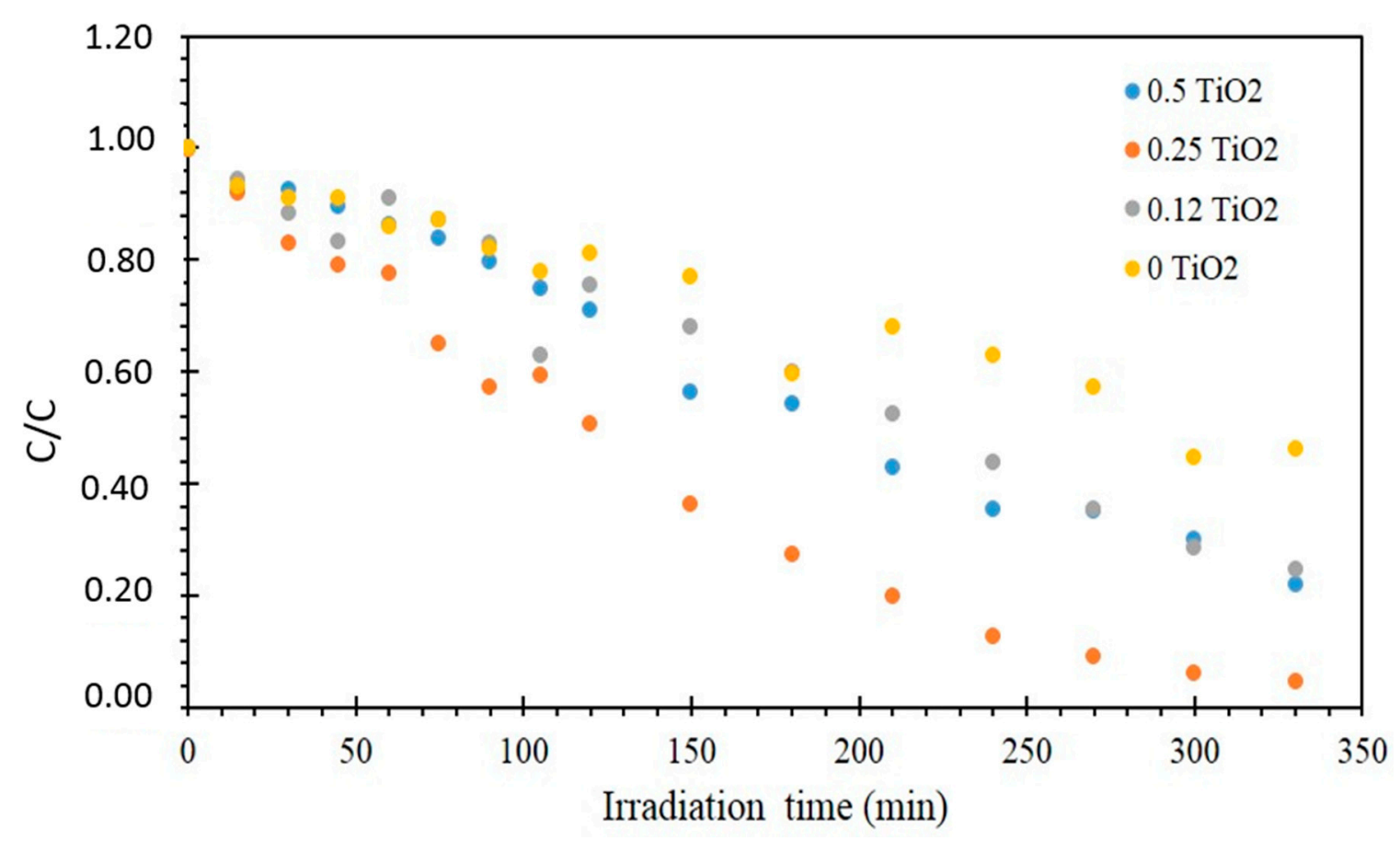

Figure 8. $\mathrm{MB}$ degradation using membranes with different amount of $\mathrm{TiO}_{2}$ under $\mathrm{UV}$ irradiation.

According to the obtained results, the membranes loaded with $\mathrm{TiO}_{2}$ exhibited significant photocatalytic activity in comparison to the pristine one ( $\mathrm{M} 2$ membrane). By increasing the $\mathrm{TiO}_{2}$ content, the photodegradation of MB increased. M6, M7, and M8, in fact, showed the $86 \%, 95 \%$, and $99 \% \mathrm{MB}$ decomposition rates after $330 \mathrm{~min}$ UV lamp irradiation, respectively.

The membrane without catalyst M2 gave $51 \%$ of MB removal due to photolysis and membrane adsorption phenomenon. The maximum MB removal rate of $99 \%$ was achieved after only $150 \mathrm{~min}$ of treatment using the $\mathrm{M} 8$ membrane corresponding to the maximum amount of $\mathrm{TiO}_{2}$ used for this study.

The curves of the reduced concentration have an exponential appearance; the kinetics of degradation of the $\mathrm{BM}$ is of pseudo-first order. It is well established in the literature that for a low initial concentration $C_{0}$, the degradation rate of organic pollutants follows the Langmuir-Hinshelwood $(\mathrm{L}-\mathrm{H})$ law. This model allows us to determine the reaction rate constant from the curve plot $\mathrm{Ln}\left(\mathrm{C} / \mathrm{C}_{0}\right)$. The plot is a line that passes through the origin; the apparent constant kapp is the slope of this line. The values of the kinetic constants, the initial rates $\mathrm{r} 0$, the degradation rate $\mathrm{X} \%$ and the time of halfreaction $\mathrm{t} 1 / 2$ are calculated and grouped in Table 5 . 
Table 5. Values of apparent constants $\left(\mathrm{k}_{\mathrm{app}}\right)$, time of half- reaction $\left(\mathrm{t}_{1 / 2}\right)$ and initial velocities $\left(\mathrm{r}_{0}\right)$ for different amounts of $\mathrm{TiO}_{2}$.

\begin{tabular}{ccccccc}
\hline Membrane Code & $\mathbf{T i O}_{\mathbf{2}}(\mathbf{\%})$ & $\mathbf{k}_{\text {app }}\left(\mathbf{m i n}^{-\mathbf{1}}\right)$ & $\mathbf{r}_{\mathbf{0}}(\mathbf{m g} \mathbf{h} \mathbf{L} \cdot \mathbf{m i n})$ & $\mathbf{t}_{\mathbf{1 / 2}}(\mathbf{m i n})$ & $\mathbf{X}(\%)$ & $\mathbf{R}^{2}$ \\
\hline M2 & 0 & 0.0022 & 0.022 & 315 & 51 & 0.928 \\
\hline M6 & 0.12 & 0.0055 & 0.051 & 126 & 86 & 0.979 \\
\hline M7 & 0.25 & 0.0084 & 0.074 & 83 & 95 & 0.952 \\
\hline M8 & 0.50 & 0.0117 & 0.117 & 59 & 99 & 0.987 \\
\hline
\end{tabular}

The half-reaction time is a very important parameter for the explanation of the elimination kinetics if we consider that $t_{1 / 2}$, is the time necessary to degrade half of the MB quantity. Therefore, the smallest half-reaction time corresponds to the best rate of degradation.

The half-reaction time increases as the reaction rate decreases. The evolution of $t_{1 / 2}$ as a function of the $\mathrm{TiO}_{2}$ content shown in Figure 9 makes possible to deduce that the difference in photoactivity is clearly reduced for the lowest $\mathrm{TiO}_{2}$ contents.

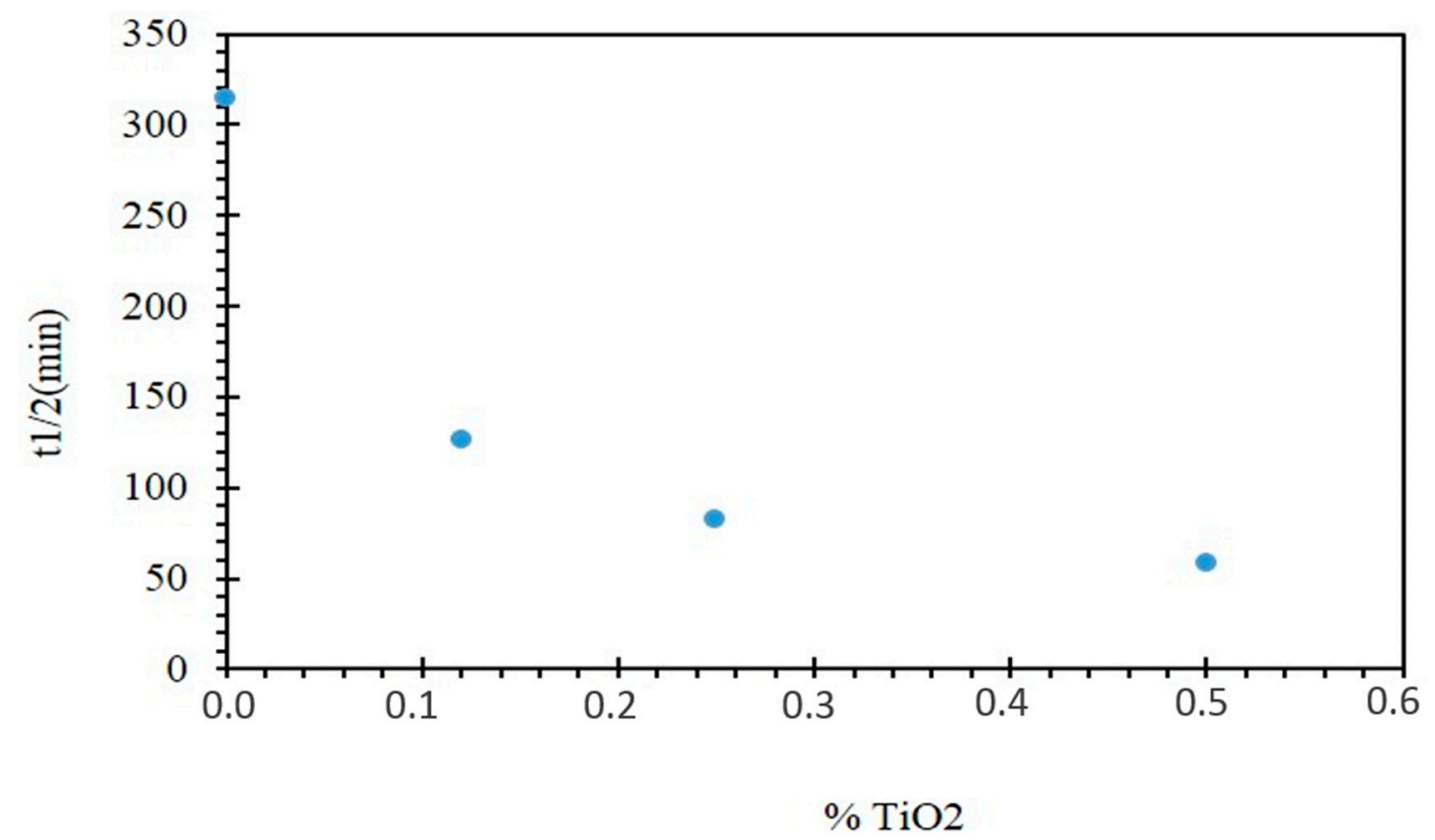

Figure 9. Evolution of $\mathrm{t}_{1 / 2}$ as a function of the $\mathrm{TiO}_{2}$ content incorporated into the membrane matrix.

These preliminary results can be considered as a starting point for a future far-reaching investigation of membranes photocatalytic activity directly measured during the operation time of the membrane (during filtration) considering, also, different organic pollutants.

\section{Experimental}

\subsection{Chemicals}

PVDF (Solef ${ }^{\circledR} 6010, \sim 322,000 \mathrm{~g} / \mathrm{mol}$ ) supplied by Solvay Specialty Polymers (Bollate, Italy) and PMMA purchased by Sigma-Aldrich 350,000 g/mol were used as polymers, TEP (Sigma-Aldrich, Milan, Italy) was used as an alternative solvent. PVP (K17, BASF, Ludwigshafen, Germany; M.W. $\sim 10,000 \mathrm{~g} / \mathrm{mol}$ ) and PEG (PEG-200, Sigma-Aldrich, Milan, Italy; M.W. 200 g/mol) were added, as pore-forming agents, to the polymeric solution. $\mathrm{TiO}_{2}$ (Aeroxide-Degussa P25) photocatalyst was dispersed in dope solution. As reported by the supplier, the $\mathrm{TiO}_{2}$ nanoparticles have a primary mean diameter of about $21 \mathrm{~nm}$, with a density of about $4 \mathrm{~g} / \mathrm{cm}^{3}$ with a predominance of the anatase form. Bi-distilled water was used as a non-solvent for polymer precipitation. 


\subsection{Membrane Preparation}

PVDF/PMMA and $\mathrm{TiO}_{2}$-PVDF/PMMA composite membranes were prepared via the phase-inversion method. The dope solution was prepared by mixing appropriate amounts of PVDF, PMMA and additives in TEP at $100{ }^{\circ} \mathrm{C}$ and continuously stirred for more than $12 \mathrm{~h}$ until a homogeneous solution was obtained. Different amount of $\mathrm{TiO}_{2}$ particles were added to the mixture. The solution was then cast on a glass plate using a manual casting knife (Elcometer 3700 Film Applicator Blade with Tank, Elcometer Instrument GmbH, Aalen, Germany) with a set thickness of $350 \mu \mathrm{m}$.

The nascent membranes were either immediately immersed in the coagulation bath (NIPS) or exposed for a variable time (5 and $10 \mathrm{~min}$ ) under controlled relative humidity (RH, 65\%) and temperature $\left(25{ }^{\circ} \mathrm{C}\right)$ in a climatic chamber (DeltaE srl, Rende (CS), Italy) before their complete coagulation into an aqueous coagulation bath (NIPS coupled with VIPS).

In order to remove solvent and additives traces, the formed membranes were then washed with hot water $\left(60{ }^{\circ} \mathrm{C}\right)$ three times consecutively. Then membranes were stored in a water bath until being used. In Table 6, a list of the produced membranes with details of dope composition and evaporation time used is reported.

Table 6. Composition of membrane casting mixture.

\begin{tabular}{|c|c|c|c|c|c|c|c|}
\hline \multirow{3}{*}{ Membrane Code } & \multicolumn{6}{|c|}{ Total Composition (wt \%) } & \multirow{3}{*}{$\begin{array}{l}\text { Evaporation } \\
\text { Time (min) }\end{array}$} \\
\hline & \multicolumn{2}{|c|}{ Polymers } & \multicolumn{3}{|c|}{ Additives } & Solvent & \\
\hline & PVDF & PMMA & PEG-200 & PVP-K17 & TiO2 & TEP & \\
\hline M0 & 6 & 6 & 0 & 0 & 0 & 88 & 2.5 \\
\hline M1 & 6 & 6 & 25 & 5 & 0 & 58 & 0 \\
\hline M2 & 6 & 6 & 25 & 5 & 0 & 58 & 2.5 \\
\hline M3 & 6 & 6 & 25 & 5 & 0 & 58 & 5 \\
\hline M4 & 5 & 5 & 25 & 5 & 0 & 60 & 2.5 \\
\hline M5 & 7 & 7 & 25 & 5 & 0 & 56 & 2.5 \\
\hline M6 & 6 & 6 & 25 & 5 & 0.12 & 57.88 & 2.5 \\
\hline M7 & 6 & 6 & 25 & 5 & 0.25 & 57.75 & 2.5 \\
\hline M8 & 6 & 6 & 25 & 5 & 0.50 & 57.50 & 2.5 \\
\hline
\end{tabular}

\subsection{Membrane Characterization}

\subsubsection{Viscosity Measurements}

The viscosity measurements of the cast solutions were conducted using a DVIII-Brookfield viscometer at $90^{\circ} \mathrm{C}$.

\subsubsection{Contact Angle Measurements}

Water contact angles $\theta$ for the top and bottom sides of the membranes were measured by an optical tensiometer (CAM100 Instrument, Nordtest srl, GI, Serravalle Scrivia (AL), Italy) via the drop method. A 3- $\mu \mathrm{L}$ bi-distilled water droplet was placed on the membrane surface. Each value was obtained immediately after dropping water. To minimize the measurement error, a total of five replicates were taken and the average was calculated.

\subsubsection{Porosity Measurement}

The membrane porosity is defined as the pore volume divided by the total volume of the membranes. Each membrane sample was weighed and subsequently submerged in a container filled with kerosene and stored for $24 \mathrm{~h}$ [89]. The test was performed three times and the porosity value was calculated. The porosity $(\varepsilon)$ was estimated using Equation (1):

$$
\varepsilon(\%)=\frac{V_{\text {Pore }}}{V_{\text {Total }}}=\frac{\left(w_{W}-w_{d}\right) / \rho_{s}}{\left(w_{w}-w_{d}\right) / \rho_{s}+\left(w_{d} / \rho_{p}\right)} \times 100
$$


where:

$w_{w}$ is the weight of the wet membrane,

$w_{d}$ is the weight of the dry membrane,

$\rho_{S}$ is the kerosene density,

$\rho_{p}$ is the polymer density.

\subsubsection{Pure Water Permeability (PWP)}

The PVDF/PMMA and PVDF/PMMA/TiO 2 membrane permeation performance experiments were conducted measuring the pure water permeability (PWP). PWP was measured at $25^{\circ} \mathrm{C}$ using a laboratory cross flow set-up. Water was fed through the membrane (area of $0.0008 \mathrm{~m}^{2}$ ) by means of a gear pump (Tuthill Pump Co., Concord, CA, USA). PWP was, then, calculated using Equation (2):

$$
P W P=\frac{Q}{A t P}
$$

where:

$Q$ is the volume of the permeate in liters,

$A$ is the membrane surface area $\left(\mathrm{m}^{2}\right)$,

$t$ is the permeation time $(\mathrm{h})$,

$P$ is the applied pressure used (bar).

A minimum of three membrane samples were tested and the tabulated results show the average values.

\subsubsection{Pore Size}

The pore size of prepared membranes was evaluated by the liquid-gas displacement technique using a Capillary Flow Porometer (CFP- 1500 AEXL, Porous Materials Inc., Ithaca, NY, USA). Membranes were soaked in Porewick ${ }^{\circledR}$ used as a wetting liquid (superficial tension 16 dyne $/ \mathrm{cm}$ ) for $24 \mathrm{~h}$ to be completely wetted. Nitrogen was gradually allowed to flow into the membrane by increasing its pressure during time. Gas pressure as well as permeation flow rates across the dry membrane were registered, allowing the final mean pore size calculation.

\subsubsection{Microscopy}

The membrane morphology was evaluated by using a Zeiss-EVO Ma10 instrument (Zeiss, Oberkochen, Germany) scanning electron microscope (SEM). Cross sections of the membranes were prepared by fracturing the membranes in liquid nitrogen. All of the membranes were coated with a thin layer of gold before scanning in order to make the samples conductive. SEM-BSD mapping was used to monitor the inter-dispersion of $\mathrm{TiO} 2$ in the membrane matrix.

\subsubsection{Mechanical Strength}

Young's modulus was measured using Zwic/Roell test unit (Ulm, Germany). For each membrane, five samples $(5 \mathrm{~cm} \times 1 \mathrm{~cm})$ were tested, the tabulated results report the average values.

\subsection{Experimental Set-up for Photocatalytic Performance}

A batch photocatalytic reactor consisted of a pyrex glass tank with a piece of membrane was placed inside a shielded chamber with UV lamp mounted on the top (lamp emission from $180 \mathrm{~nm}$ to visible light-500 W-Purchased from Helios Italquarz s.r.l., Cambiago (MI), Italy).

MB degradation experiments were carried out for $10 \mu \mathrm{mol}$ feed solution. Flat sheet membranes containing different quantities of $\mathrm{TiO}_{2}(0.12,0.25$, and $0.5 \mathrm{wt} \%)$ were prepared by phase inversion 
technique. Membranes with the same surface dimension $(4 \mathrm{~cm} \times 4 \mathrm{~cm})$ were immersed in $400 \mathrm{~mL}$ feed solution as described in Figure 10.

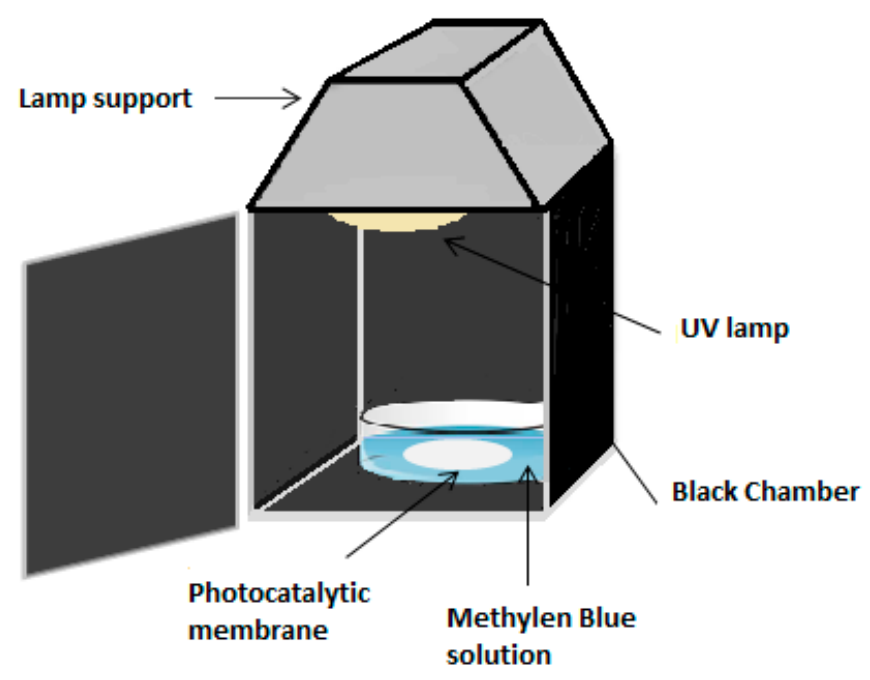

Figure 10. Schematic picture of the photocatalytic set-up.

Adsorption tests were carried out in the dark for $30 \mathrm{~min}$ before lighting the UV lamp for all experiments. The decomposition of the $\mathrm{MB}$ was carried out at ambient temperature in the batch reactor described in Figure 10. The photocatalytic tests were carried out by immersing M2, M6, M7, and M8 membranes in $500 \mathrm{~mL}$ of BM solution with an initial concentration $10 \mu \mathrm{mol} / \mathrm{L}$ under UV lamp irradiation.

The photocatalytic degradation of MB for both initial concentration and irradiated samples was determined by UV-Vis spectrophotometer analysis (Shimadzu UV-1601, Kyoto, Japan) following the decrease of dye absorption as a consequence of its degradation. A calibration curve of MB solution obtained at $664.5 \mathrm{~nm}$ wavelengths for different concentrations was prepared in order to correlate the concentration of $\mathrm{MB}$ at different reaction times by converting the absorbance of the sample to $\mathrm{MB}$ concentration.

\section{Conclusions}

In this study porous PVDF/PMMA membranes and $\mathrm{TiO}_{2}-\mathrm{PVDF} / \mathrm{PMMA}$ blend membranes were prepared by the phase inversion method using TEP as an alternative solvent by evaluating the effect of different preparation and operation conditions. The effects of evaporation time, additives and polymer content on morphology, mechanical stability and membrane performance were, in fact, systematically investigated. Furthermore, the effect of the $\mathrm{TiO}_{2}$ addition to the PVDF/PMMA membranes was evaluated in terms of membrane properties and photocatalytic activity.

The morphology and the physical properties of the prepared membranes were found to be dependent both on the composition of the casting dope solution and on the phase inversion technique adopted (NIPS or VIPS/NIPS). The results can be, therefore, summarized as follows:

- The membranes produced via the NIPS-VIPS procedure showed a significant change in the morphology of the membrane, from a dense to a porous structure in the range of UF/MF. The pore size was also improved with a subsequent decrease of membranes mechanical properties.

- The presence of hydrophilic additives such as PVP and PEG induced a morphological evolution from a very dense structure to a porous one. The additives enhanced the porosity of the membrane favoring the formation of a more open structure with an increase in pore size.

- The addition of different amount of $\mathrm{TiO}_{2}$ led to an increase in membrane pore size, improving hydrophilic nature and mechanical properties of the membranes. 
- The photocatalytic membranes developed showed promising results in terms of MB photodegradation (up to $99 \%$ ) making these membranes potential candidates for the treatment and purification of wastewater.

Supplementary Materials: The following are available online, Figures S1-S4.

Author Contributions: Conceptualization, H.M. and A.F.; Data curation, O.B. and F.G.; Investigation, O.B., F.G. and T.M.; Methodology, O.B.; Supervision, F.G., T.M., H.M., H.L. and A.F.; Validation, H.M., H.L. and A.F.; Writing—original draft, O.B.; Writing—review and editing, F.G., T.M., H.M., and A.F.

Acknowledgments: This work was supported by the Institute on Membrane Technology of the National Research Council (ITM-CNR, Italy) in Rende (CS) (Italy) with collaboration of the Ministry of Higher Education and Scientific Research (MESRS) of Algeria under the Exceptional National Program (PNE).

Conflicts of Interest: The authors declare no conflict of interest.

\section{References}

1. Dunn, P.J. The importance of Green Chemistry in Process Research and Development. Chem. Soc. Rev. 2012. [CrossRef] [PubMed]

2. Baños, R.; Manzano-Agugliaro, F.; Montoya, F.G.; Gil, C.; Alcayde, A.; Gómez, J. Optimization methods applied to renewable and sustainable energy: A review. Renew. Sustain. Energy Rev. 2011, 15, 1753-1766. [CrossRef]

3. Anastas, P.T. Green Chemistry and the role of analytical methodology development. Crit. Rev. Anal. Chem. 1999. [CrossRef]

4. Robinson, T.; McMullan, G.; Marchant, R.; Nigam, P. Remediation of dyes in textile effluent: A critical review on current treatment technologies with a proposed alternative. Bioresour. Technol. 2001, 77, 247-255. [CrossRef]

5. Konstantinou, I.K.; Albanis, T.A. $\mathrm{TiO}_{2}$-assisted photocatalytic degradation of azo dyes in aqueous solution: Kinetic and mechanistic investigations: A review. Appl. Catal. B Environ. 2004. [CrossRef]

6. Chin, S.S.; Chiang, K.; Fane, A.G. The stability of polymeric membranes in a $\mathrm{TiO}_{2}$ photocatalysis process. J. Memb. Sci. 2006. [CrossRef]

7. Slokar, Y.M.; Le Marechal, A.M. Methods of decoloration of textile wastewaters. Dyes Pigment 1998. [CrossRef]

8. Xi, W.; Geissen, S.U. Separation of titanium dioxide from photocatalytically treated water by cross-flow microfiltration. Water Res. 2001. [CrossRef]

9. Dijkstra, M.F.J.; Buwalda, H.; de Jong, A.W.F.; Michorius, A.; Winkelman, J.G.M.; Beenackers, A.A.C.M. Experimental comparison of three reactor designs for photocatalytic water purification. Chem. Eng. Sci. 2001. [CrossRef]

10. Meriläinen, A.; Seppälä, A.; Kauranen, P. Minimizing specific energy consumption of oxygen enrichment in polymeric hollow fiber membrane modules. Appl. Energy 2012. [CrossRef]

11. Peng, N.; Widjojo, N.; Sukitpaneenit, P.; Teoh, M.M.; Lipscomb, G.G.; Chung, T.S.; Lai, J.Y. Evolution of polymeric hollow fibers as sustainable technologies: Past, present, and future. Prog. Polym. Sci. 2012. [CrossRef]

12. Gupta, S.M.; Tripathi, M. A review of $\mathrm{TiO}_{2}$ nanoparticles. Chin. Sci. Bull. 2011, 56, 1639-1657. [CrossRef]

13. Tomé, L.C.; Mecerreyes, D.; Freire, C.S.R.; Rebelo, L.P.N.; Marrucho, I.M. Pyrrolidinium-based polymeric ionic liquid materials: $\mathrm{New}$ perspectives for $\mathrm{CO}_{2}$ separation membranes. J. Membr. Sci. 2013. [CrossRef]

14. Ravanchi, M.T.; Kaghazchi, T.; Kargari, A. Application of membrane separation processes in petrochemical industry: A review. Desalination 2009. [CrossRef]

15. Atadashi, I.M.; Aroua, M.K.; Aziz, A.R.A.; Sulaiman, N.M.N. Membrane biodiesel production and refining technology: A critical review. Renew. Sustain. Energy Rev. 2011. [CrossRef]

16. Kim, J.; van der Bruggen, B. The use of nanoparticles in polymeric and ceramic membrane structures: Review of manufacturing procedures and performance improvement for water treatment. Environ. Pollut. 2010. [CrossRef] [PubMed]

17. Shirazi, M.M.A.; Bastani, D.; Kargari, A.; Tabatabaei, M. Characterization of polymeric membranes for membrane distillation using atomic force microscopy. Desalin. Water Treat. 2013, 51, 6003-6008. [CrossRef] 
18. Mirtalebi, E.; Shirazi, M.M.A.; Kargari, A.; Tabatabaei, M.; Ramakrishna, S. Assessment of atomic force and scanning electron microscopes for characterization of commercial and electrospun nylon membranes for coke removal from wastewater. Desalin. Water Treat. 2014. [CrossRef]

19. Shirazi, M.J.A.; Bazgir, S.; Shirazi, M.M.A.; Ramakrishna, S. Coalescing filtration of oily wastewaters: Characterization and application of thermal treated, electrospun polystyrene filters. Desalin. Water Treat. 2013. [CrossRef]

20. Bet-Moushoul, E.; Mansourpanah, Y.; Farhadi, K.; Tabatabaei, M. $\mathrm{TiO}_{2}$ nanocomposite based polymeric membranes: A review on performance improvement for various applications in chemical engineering processes. Chem. Eng. J. 2016. [CrossRef]

21. Akbari, A.; Remigy, J.C.; Aptel, P. Treatment of textile dye effluent using a polyamide-based nanofiltration membrane. Chem. Eng. Process. 2002. [CrossRef]

22. Galiano, F.; Figoli, A.; Ahmed, S.; Johnson, D.; Altinkaya, A.; Veltri, L.; de Luca, G.; Mancuso, R.; Hilal, N.; Gabriele, B.; et al. A step forward to a more ef fi cient wastewater treatment by membrane surface modi fi cation via polymerizable bicontinuous microemulsion. J. Membr. Sci. 2015, 482, 103-114. [CrossRef]

23. Galiano, F.; Friha, I.; Deowan, S.A.; Hoinkis, J.; Xiaoyun, Y.; Johnson, D.; Mancuso, R.; Hilal, N.; Gabriele, B.; Sayadi, S.; et al. Novel low-fouling membranes from lab to pilot application in textile wastewater treatment. J. Colloid Interface Sci. 2018, 515, 208-220. [CrossRef] [PubMed]

24. Deowan, S.A.; Galiano, F.; Hoinkis, J.; Johnson, D.; Altinkaya, S.A.; Gabriele, B.; Hilal, N.; Drioli, E.; Figoli, A. Novel low-fouling membrane bioreactor (MBR) for industrial wastewater treatment. J. Membr. Sci. 2016, 510, 524-532. [CrossRef]

25. Galiano, F.; Schmidt, S.A.; Ye, X.; Kumar, R.; Mancuso, R.; Curcio, E.; Gabriele, B.; Hoinkis, J.; Figoli, A. UV-LED induced bicontinuous microemulsions polymerisation for surface modification of commercial membranes-Enhancing the antifouling properties. Sep. Purif. Technol. 2018. [CrossRef]

26. Fu, J.; Ji, M.; Wang, Z.; Jin, L.; An, D. A new submerged membrane photocatalysis reactor (SMPR) for fulvic acid removal using a nano-structured photocatalyst. J. Hazard. Mater. 2006. [CrossRef] [PubMed]

27. Leong, S.; Razmjou, A.; Wang, K.; Hapgood, K.; Zhang, X.; Wang, $\mathrm{H}_{\text {. }} \mathrm{TiO}_{2}$ based photocatalytic membranes: A review. J. Membr. Sci. 2014, 472, 167-184. [CrossRef]

28. Mozia, S. Photocatalytic membrane reactors (PMRs) in water and wastewater treatment: A review. Sep. Purif. Technol. 2010, 73, 71-91. [CrossRef]

29. Kim, S.H.; Kwak, S.-Y.; Sohn, B.-H.; Park, T.H. Design of $\mathrm{TiO}_{2}$ nanoparticle self-assembled aromatic polyamide thin-film-composite (TFC) membrane as an approach to solve biofouling problem. J. Membr. Sci. 2003, 211, 157-165. [CrossRef]

30. Zhang, W.; Ding, L.; Luo, J.; Jaffrin, M.Y.; Tang, B. Membrane fouling in photocatalytic membrane reactors (PMRs) for water and wastewater treatment: A critical review. Chem. Eng. J. 2016. [CrossRef]

31. Lloyd, D.R.; Kinzer, K.E.; Tseng, H.S. Microporous membrane formation via thermally induced phase separation. I. Solid-liquid phase separation. J. Membr. Sci. 1990, 52, 239-261. [CrossRef]

32. Li, X.; Lu, X. Morphology of polyvinylidene fluoride and its blend in thermally induced phase separation process. J. Appl. Polym. Sci. 2006. [CrossRef]

33. Nunes, S.P.; Peinemann, K.V. Ultrafiltration membranes from PVDF/PMMA blends. J. Membr. Sci. 1992. [CrossRef]

34. Maiti, P.; Nandi, A.K. Influence of chain structure on the crystallization mechanism of poly(vinylidene fluoride)/poly(methyl acrylate) blends: Evidence of chain extension due to blending. Polymer (Guildf) 1998, 39, 413-421. [CrossRef]

35. Bottino, A.; Capannelli, G.; Monticelli, O.; Piaggio, P. Poly(vinylidene fluoride) with improved functionalization for membrane production. J. Membr. Sci. 2000. [CrossRef]

36. Kim, K.J.; Cho, Y.J.; Kim, Y.H. Factors determining the formation of the $\beta$ crystalline phase of poly(vinylidene fluoride) in poly(vinylidene fluoride)-poly(methyl methacrylate) blends. Vib. Spectrosc. 1995, 9, 147-159.

37. Ma, W.; Zhang, J.; Wang, X.; Wang, S. Effect of PMMA on crystallization behavior and hydrophilicity of poly(vinylidene fluoride)/poly(methyl methacrylate) blend prepared in semi-dilute solutions. Appl. Surf. Sci. 2007. [CrossRef]

38. Rajabzadeh, S.; Maruyama, T.; Ohmukai, Y.; Sotani, T.; Matsuyama, H. Preparation of PVDF/PMMA blend hollow fiber membrane via thermally induced phase separation (TIPS) method. Sep. Purif. Technol. 2009. [CrossRef] 
39. Huang, C.; Zhang, L. Miscibility of poly(vinylidene fluoride) and atactic poly(methyl methacrylate). J. Appl. Polym. Sci. 2004, 92, 1-5. [CrossRef]

40. Ma, W.; Zhang, J.; Wang, X. Crystallizaion and surface morphology of poly(vinylidene fluoride)/poly(methylmethacrylate) films by solution casting on different substrates. Appl. Surf. Sci. 2008, 254, 2947-2954. [CrossRef]

41. Cui, Z.-Y.; Xu, Y.-Y.; Zhu, L.-P.; Wei, X.-Z.; Zhang, C.-F.; Zhu, B.-K. Preparation of PVDF/PMMA blend microporous membranes for lithium ion batteries via thermally induced phase separation process. Mater. Lett. 2008, 62, 3809-3811. [CrossRef]

42. Zhang, H.P.; Zhang, P.; Li, Z.H.; Sun, M.; Wu, Y.P.; Wu, H.Q. A novel sandwiched membrane as polymer electrolyte for lithium ion battery. Electrochem. Commun. 2007, 9, 1700-1703. [CrossRef]

43. Jeon, M.Y.; Kim, C.K. Phase behavior of polymer/diluent/diluent mixtures and their application to control microporous membrane structure. J. Membr. Sci. 2007. [CrossRef]

44. Ochoa, N.A.; Masuelli, M.; Marchese, J. Effect of hydrophilicity on fouling of an emulsified oil wastewater with PVDF/PMMA membranes. J. Membr. Sci. 2003, 226, 203-211. [CrossRef]

45. Zhou, L.; Wu, N.; Cao, Q.; Jing, B.; Wang, X.; Wang, Q.; Kuang, H. A novel electrospun PVDF/PMMA gel polymer electrolyte with in situ $\mathrm{TiO}_{2}$ for Li-ion batteries. Solid State Ionics 2013. [CrossRef]

46. Lin, D.-J.; Chang, C.-L.; Lee, C.-K.; Cheng, L.-P. Preparation and characterization of microporous PVDF/PMMA composite membranes by phase inversion in water/DMSO solutions. Eur. Polym. J. 2006, 42, 2407-2418. [CrossRef]

47. Ai, F.; Li, H.; Wang, Q.; Yuan, W.Z.; Chen, X.; Yang, L.; Zhao, J.; Zhang, Y. Surface characteristics and blood compatibility of PVDF/PMMA membranes. J. Mater. Sci. 2012, 47, 5030-5040. [CrossRef]

48. Li, Z.; Wei, J.; Shan, F.; Yang, J.; Wang, X. PVDF/PMMA brushes membrane for lithium-ion rechargeable batteries prepared via preirradiation grafting technique. J. Polym. Sci. Part B Polym. Phys. 2008. [CrossRef]

49. Galiano, F.; Ghanim, A.H.; Rashid, K.T.; Marino, T.; Simone, S.; Alsalhy, Q.F.; Figoli, A. Preparation and characterization of green polylactic acid (PLA) membranes for organic/organic separation by pervaporation. Clean Technol. Environ. Policy 2019, 21, 109-120. [CrossRef]

50. Byrne, F.P.; Jin, S.; Paggiola, G.; Petchey, T.H.M.; Clark, J.H.; Farmer, T.J.; Hunt, A.J.; McElroy, C.R.; Sherwood, J. Tools and techniques for solvent selection: Green solvent selection guides. Sustain. Chem. Process. 2016. [CrossRef]

51. CDH Finechemical, Material Safety Data Sheet, (n.d.). Available online: https://www.cdhfinechemical.com/ images/product/msds/37_1771179379_TRIETHYLPHOSPHATECASNO78-40-0MSDS.pdf (accessed on 20 September 2002).

52. Chang, J.; Zuo, J.; Zhang, L.; O’Brien, G.S.; Chung, T.S. Using green solvent, triethyl phosphate (TEP), to fabricate highly porous PVDF hollow fiber membranes for membrane distillation. J. Membr. Sci. 2017. [CrossRef]

53. Li, Y.; Jin, C.; Peng, Y.; An, Q.; Chen, Z.; Zhang, J.; Ge, L.; Wang, S. Fabrication of PVDF hollow fiber membranes via integrated phase separation for membrane distillation. J. Taiwan Inst. Chem. Eng. 2019, 95, 487-494. [CrossRef]

54. Fadhil, S.; Marino, T.; Makki, H.F.; Alsalhy, Q.F.; Blefari, S.; Macedonio, F.; di Nicolò, E.; Giorno, L.; Drioli, E.; Figoli, A. Novel PVDF-HFP flat sheet membranes prepared by triethyl phosphate (TEP) solvent for direct contact membrane distillation. Chem. Eng. Process. Process Intensif. 2016, 102, 16-26. [CrossRef]

55. Lin, D.J.; Chang, C.L.; Chen, T.C.; Cheng, L.P. Microporous PVDF membrane formation by immersion precipitation from water/TEP/PVDF system. Desalination 2002. [CrossRef]

56. Marino, T.; Russo, F.; Figoli, A. The formation of polyvinylidene fluoride membranes with tailored properties via vapour/non-solvent induced phase separation. Membranes (Basel) 2018, 8, 71. [CrossRef] [PubMed]

57. Lin, Y.; Tang, Y.; Ma, H.; Yang, J.; Tian, Y.; Ma, W.; Wang, X. Formation of a bicontinuous structure membrane of polyvinylidene fluoride in diphenyl carbonate diluent via thermally induced phase separation. J. Appl. Polym. Sci. 2009. [CrossRef]

58. Liu, M.; Xu, Z.; Chen, D.; Wei, Y. Preparation and characterization of microporous PVDF membrane by thermally induced phase separation from a ternary polymer/solvent/non-solvent system. Desalin. Water Treat. 2010, 17, 183-192. [CrossRef] 
59. Sawada, S.; Ursino, C.; Galiano, F.; Simone, S.; Drioli, E.; Figoli, A. Effect of citrate-based non-toxic solvents on poly(vinylidene fluoride) membrane preparation via thermally induced phase separation. J. Membr. Sci. 2015, 493, 232-242. [CrossRef]

60. Ali, A.; Yunus, R.M.; Awang, M.; Mat, R. The Effects of Evaporation Time on Morphological Structure of Polysulfone/Cellulose Acetate Phthalate/Polyvinylpyrrolidone (PSf/CAP/PVP) Blend Membranes. Appl. Mech. Mater. 2014, 695, 77-80. [CrossRef]

61. Sharpe, I.D.; Ismail, A.F.; Shilton, S.J. A study of extrusion shear and forced convection residence time in the spinning of polysulfone hollow fiber membranes for gas separation. Sep. Purif. Technol. 1999. [CrossRef]

62. Marino, T.; Galiano, F.; Simone, S.; Figoli, A. DMSO EVOL ${ }^{\mathrm{TM}}$ as novel non-toxic solvent for polyethersulfone membrane preparation. Environ. Sci. Pollut. Res. 2018. [CrossRef] [PubMed]

63. Gzara, L.; Rehan, Z.A.; Simone, S.; Galiano, F.; Hassankiadeh, N.T.; Al-Sharif, S.F.; Figoli, A.; Drioli, E. Tailoring PES membrane morphology and properties via selected preparation parameters. J. Polym. Eng. 2017. [CrossRef]

64. Chakrabarty, B.; Ghoshal, A.K.; Purkait, M.K. Ultrafiltration of stable oil-in-water emulsion by polysulfone membrane. J. Membr. Sci. 2008, 325, 427-437. [CrossRef]

65. Panda, S.R.; De, S. Effects of polymer molecular weight, concentration, and role of polyethylene glycol as additive on polyacrylonitrile homopolymer membranes. Polym. Eng. Sci. 2014. [CrossRef]

66. Sadeghi, I.; Aroujalian, A.; Raisi, A.; Dabir, B.; Fathizadeh, M. Surface modification of polyethersulfone ultrafiltration membranes by corona air plasma for separation of oil/water emulsions. J. Membr. Sci. 2013, 430, 24-36. [CrossRef]

67. Panda, S.R.; Bhandaru, N.; Mukherjee, R.; De, S. Ultrafiltration of oily waste water: Contribution of surface roughness in membrane properties and fouling characteristics of polyacrylonitrile membranes. Can. J. Chem. Eng. 2015, 93, 2031-2042. [CrossRef]

68. Quéré, D. Rough ideas on wetting. Phys. A Stat. Mech. Appl. 2002. [CrossRef]

69. Wenzel, R.N. Resistance of solid surfaces to wetting by water. Ind. Eng. Chem. 1936, 988-994. [CrossRef]

70. Ahmad, A.L.; Ideris, N.; Ooi, B.S.; Low, S.C.; Ismail, A. Influence of Polymer Concentration on PVDF Membrane Fabrication for Immunoassay Analysis. J. Appl. Sci. 2014, 12, 1299-1303.

71. Saljoughi, E.; Sadrzadeh, M.; Mohammadi, T. Effect of preparation variables on morphology and pure water permeation flux through asymmetric cellulose acetate membranes. J. Membr. Sci. 2009. [CrossRef]

72. Rajabzadeh, S.; Liang, C.; Ohmukai, Y.; Maruyama, T.; Matsuyama, H. Effect of additives on the morphology and properties of poly(vinylidene fluoride) blend hollow fiber membrane prepared by the thermally induced phase separation method. J. Membr. Sci. 2012. [CrossRef]

73. Torrestiana-Sanchez, B.; Ortiz-Basurto, R.I.; la Fuente, E.B. Effect of nonsolvents on properties of spinning solutions and polyethersulfone hollow fiber ultrafiltration membranes. J. Membr. Sci. 1999. [CrossRef]

74. Yeow, M.L.; Liu, Y.; Li, K. Preparation of porous PVDF hollow fibre membrane via a phase inversion method using lithium perchlorate ( $\mathrm{LiClO} 4)$ as an additive. J. Membr. Sci. 2005. [CrossRef]

75. Ismail, A.F.; Mustaffar, M.I.; Illias, R.M.; Abdullah, M.S. Effect of dope extrusion rate on morphology and performance of hollow fibers membrane for ultrafiltration. Sep. Purif. Technol. 2006. [CrossRef]

76. Chen, H.P.; Liu, L.F.; Yang, F.L. Effects of ATRP grafted PMMA-co-PSBMA-TiO 2 nano-particles on the property and performance of PVDF microfiltration membranes. Procedia Eng. 2012. [CrossRef]

77. Liu, L.; Chen, H.; Yang, F. Enhancing membrane performance by blending ATRP grafted $\mathrm{PMMA}-\mathrm{TiO}_{2}$ or PMMA-PSBMA-TiO ${ }_{2}$ in PVDF. Sep. Purif. Technol. 2014. [CrossRef]

78. Yang, C.L.; Li, Z.H.; Li, W.J.; Liu, H.Y.; Xiao, Q.Z.; Lei, G.T.; Ding, Y.H. Batwing-like polymer membrane consisting of PMMA-grafted electrospun $\mathrm{PVdF}_{-} \mathrm{SiO}_{2}$ nanocomposite fibers for lithium-ion batteries. J. Membr. Sci. 2015. [CrossRef]

79. Song, D.Y.; Xu, C.; Chen, Y.F.; He, J.R.; Zhao, Y.; Li, P.J.; Lin, W.; Fu, F. Enhanced thermal and electrochemical properties of PVDF-HFP/PMMA polymer electrolyte by $\mathrm{TiO}_{2}$ nanoparticles. Solid State Ionics 2015. [CrossRef]

80. Ahmadian-Alam, L.; Kheirmand, M.; Mahdavi, H. Preparation, characterization and properties of PVDF-g-PAMPS/PMMA-co-PAMPS/silica nanoparticle as a new proton exchange nanocomposite membrane. Chem. Eng. J. 2016. [CrossRef]

81. Oh, S.J.; Kim, N.; Lee, Y.T. Preparation and characterization of $\mathrm{PVDF} / \mathrm{TiO}_{2}$ organic-inorganic composite membranes for fouling resistance improvement. J. Membr. Sci. 2009. [CrossRef] 
82. Zhao, X.; Zhang, W.; Chen, S.; Zhang, J.; Wang, X. Hydrophilicity and crystallization behavior of $\mathrm{PVDF} / \mathrm{PMMA} / \mathrm{TiO}_{2}\left(\mathrm{SiO}_{2}\right)$ composites prepared by in situ polymerization. J. Polym. Res. 2012. [CrossRef]

83. Galiano, F.; Song, X.; Marino, T.; Boerrigter, M.; Saoncella, O.; Simone, S.; Faccini, M.; Chaumette, C.; Drioli, E.; Figoli, A. Novel Photocatalytic PVDF/Nano-TiO ${ }_{2}$ Hollow Fibers for Environmental Remediation. Polymers (Basel) 2018, 10, 1134. [CrossRef]

84. Yang, Y.; Wang, P.; Zheng, Q. Preparation and properties of polysulfone/ $\mathrm{TiO}_{2}$ composite ultrafiltration membranes. J. Polym. Sci. Part B Polym. Phys. 2006, 44, 879-887. [CrossRef]

85. Jeon, J.-D.; Kim, M.-J.; Kwak, S.-Y. Effects of addition of $\mathrm{TiO}_{2}$ nanoparticles on mechanical properties and ionic conductivity of solvent-free polymer electrolytes based on porous $\mathrm{P}(\mathrm{VdF}-\mathrm{HFP}) / \mathrm{P}(\mathrm{EO}-\mathrm{EC})$ membranes. J. Power Sources. 2006, 162, 1304-1311. [CrossRef]

86. Li, J.-F.; Xu, Z.-L.; Yang, H.; Yu, L.-Y.; Liu, M. Effect of $\mathrm{TiO}_{2}$ nanoparticles on the surface morphology and performance of microporous PES membrane. Appl. Surf. Sci. 2009, 255, 4725-4732. [CrossRef]

87. Luo, M.L.; Zhao, J.Q.; Tang, W.; Pu, C.S. Hydrophilic modification of poly(ether sulfone) ultrafiltration membrane surface by self-assembly of $\mathrm{TiO}_{2}$ nanoparticles. Appl. Surf. Sci. 2005. [CrossRef]

88. Fischer, K.; Schulz, P.; Atanasov, I.; Latif, A.A.; Thomas, I.; Kühnert, M.; Prager, A.; Griebel, J.; Schulze, A. Synthesis of High Crystalline $\mathrm{TiO}_{2}$ Nanoparticles on a Polymer Membrane to Degrade Pollutants from Water. Catalysts 2018, 18, 376. [CrossRef]

89. Figoli, A.; Ursino, C.; Galiano, F.; di Nicolò, E.; Campanelli, P.; Carnevale, M.C.; Criscuoli, A. Innovative hydrophobic coating of perfluoropolyether (PFPE) on commercial hydrophilic membranes for DCMD application. J. Membr. Sci. 2017, 522, 192-201. [CrossRef]

Sample Availability: Samples of the compounds are available from the authors.

(C) 2019 by the authors. Licensee MDPI, Basel, Switzerland. This article is an open access article distributed under the terms and conditions of the Creative Commons Attribution (CC BY) license (http://creativecommons.org/licenses/by/4.0/). 